\title{
All natural habitat edges matter equally for endangered Maculinea butterflies
}

\author{
Piotr Nowicki • Wiktor Halecki · Konrad Kalarus
}

Received: 24 January 2012/ Accepted: 19 April 2012/Published online: 4 May 2012

(C) The Author(s) 2012. This article is published with open access at Springerlink.com

\begin{abstract}
An obvious consequence of habitat fragmentation is an increasing role of habitat edges for species survival. Recently it has been suggested that the endangered butterfly Maculinea nausithous prefers forested edges of its meadow habitats. However, the prevalence of forests in the study area used for this analysis makes it impossible to distinguish whether the effect detected is a genuine preference for forest edges or a preference for any natural patch edges as opposed to patch interiors. We investigated habitat selection by Maculinea nausithous and Maculinea teleius occurring sympatrically at five habitat patches surrounded by mosaic landscape. Butterfly capture positions were marked with GPS and subsequently analysed with GIS software. Both species avoided the interiors of their patches and concentrated in the edge zone, but these preferences were visible only at three larger patches exceeding 1 ha in area. Among different types of edges those bordering densely built-up areas were avoided, whereas all natural edges (adjacent to forests, reeds or grasslands) were similarly used. We hypothesise that preferences towards natural patch edges, regardless of their type, can be explained by the spatial interactions between Maculinea butterflies and Myrmica ants they parasitise. Patch surroundings constitute refuge space for the ants, and hence their densities may be expected to be higher near patch edges. Our findings indicate the importance of patch
\end{abstract}

P. Nowicki $(\bowtie) \cdot$ W. Halecki $\cdot$ K. Kalarus

Institute of Environmental Sciences, Jagiellonian University, Gronostajowa 7, 30-387 Kraków, Poland

e-mail: piotr.nowicki@uj.edu.pl

Present Address:

W. Halecki

Agricultural University, 29 Listopada 48, 31-425 Kraków, Poland surroundings for the persistence of Maculinea populations. Regretfully, current legal framework makes it difficult to protect patch surroundings, where neither priority species nor their habitats occur.

Keywords Fragmentation - Habitat selection - Maculinea nausithous - Maculinea teleius · Mosaic landscape · Myrmica ants

\section{Introduction}

One of obvious consequences of habitat fragmentation is the fact that species experience edge effects more frequently (Primack 2002; Fahrig 2003). There have been numerous general analyses of edge effects on patterns of species richness and diversity (e.g. Yahner 1988; Kiviniemi and Eriksson 2002; Yamaura et al. 2008; van Halder et al. 2011), but studies documenting avoidance or preference of habitat edges by particular species of conservation interest, the results of which could be used in conservation practice, have been less popular (see reviews in Fahrig 2003; Ries et al. 2004). Furthermore, species-specific studies of edge use have been predominantly conducted in vertebrates, especially mammals and birds, and considerably less abundant in other taxa (Ries et al. 2004; Fletcher et al. 2007). In butterflies, the responses to habitat edges have been typically investigated in the context of their influence on dispersal (e.g. Haddad 1999; Ries and Debinski 2001; Schultz and Crone 2001; Schtickzelle and Baguette 2003), while the issue of edge-related habitat preferences has been somewhat neglected (Hambäck et al. 2010; but see Ries and Sisk 2008).

Recently Kőrösi et al. (2012) presented an insightful small-scale analysis of habitat selection by endangered wet 
meadow butterflies of the genus Maculinea (=Phengaris; while the latter synonym should have the priority, the use of the name Maculinea is also allowed-see ICZN 2011, and we have decided to stick to it for the sake of consistency with earlier papers). Their findings indicated strong preference towards forest edges in M. nausithous (Bergsträsser, 1779), and lack of such preference in M. teleius (Bergsträsser, 1779). Similarly, an earlier landscape-scale study by the same team showed that $M$. nausithous concentrated along tree-lined edges of their habitat patches, whereas M. teleius was more abundant along road edges (Batáry et al. 2009). While we acknowledge the profundity of the results obtained in specific environmental context, we are not convinced about their generality, because the characteristics of the study areas did not allow to examine preferences towards other edge types. This is particularly true in the case of the study by Körösi et al. (2012), who worked in a region where Maculinea habitats were surrounded by forests and all the edges were forest ones. Consequently, it is impossible to distinguish whether the effect they detected in M. nausithous really stems from the preference towards forest edges and not just towards any peripheral fragments of habitat patches. Although from the purely scientific point of view the distinction may appear minor, it has serious conservation implications, especially that Maculinea butterflies enjoy the status of flagships of biodiversity conservation in Europe and they are the target of a growing number of conservation programmes (Settele et al. 2005; Thomas et al. 2009, 2011).

Our intention was to solve the above problem by investigating habitat selection by Maculinea butterflies in a region where their wet meadow habitats are located in a heterogeneous landscape and thus various types of edges are present. We tested the following hypotheses: (1) Maculinea butterflies prefer patch edges regardless of their type, and (2) preference towards edges is moderated by patch size.

\section{Materials and methods}

Field sampling

The study was conducted in the Kraków region, southern Poland, where large sympatric metapopulations of $M$. nausithous and $M$. teleius exist in a mosaic landscape (Nowicki et al. 2007). The region includes more than 50 patches with Sanguisorba officinalis, which is the foodplant of both species and defines the spatial limits of their local populations (Thomas et al. 1998). All the habitat patches were mapped with ca. $1 \mathrm{~m}$ precision using GPS Magellan ProMark X (Magellan System Corp., USA). Intensive mark-release-recapture sampling was carried out at three patches (named $\mathrm{K} 9, \mathrm{~K} 17$, and $\mathrm{K} 18$ ) in the summer 2003, and two other patches (K73 and K74) in the summer 2008 (Fig. 1). All the patches are located in the relatively isolated easternmost fragment of the region.

Butterflies were captured on roughly every third day between 9:00 and 17:00. Each specimen netted was individually marked with a number written on the underside of its hind right wing using fine-tipped water-proof marker Staedler 313, and immediately released. We recorded geographic position of each capture (with ca. $3 \mathrm{~m}$ precision) applying GPS Garmin 12XL (Olathe, USA). Sampling intensity was standardised in order to ensure uniform capture probabilities within entire area of each patch as well as among patches (Nowicki et al. 2005a; see this reference for further details of the mark-recapture surveys).

Analysis

The data were analysed separately for each species and patch. The location points of butterflies captures were processed with the GIS software Idrisi 2.0 (Eastman 1997). For each capture point its distance from the habitat patch boundary was derived and it constituted the basis for the statistical analyses. Due to the home range behaviour of Maculinea butterflies and the resulting spatial autocorrelation of their capture points (cf. Hovestadt and Nowicki 2008), only one randomly selected capture point per individual was used in all the analyses except for that of butterfly movements (see below).

The initial step was testing for inter-sexual differences in the capture point locations. The distances-from-boundary of male and female capture points were compared using Student's two sample $t$ test, with logarithmic transformation applied to achieve normality of the distance distributions (Table 1). As the testing revealed no significant differences in any case (invariably $P>0.5$ ), the data for both sexes were pooled together for all the further analyses.

In order to check whether Maculinea butterflies concentrate near habitat patch edges we subsequently compared mean distances from patch boundary of their capture points with GIS-derived means for the entire surface of each patch. The latter values represent the mean distancefrom-boundary of capture points expected in the case of their random distribution. The comparisons were performed using Student's one sample $t$ test, again on logtransformed data.

Capture point concentrations near patch edges may not necessarily indicate Maculinea preferences for these fragments. Equally well, they may stem from the fact that although the butterflies can move freely within patch interior, patch boundaries constitute a barrier, potentially halting their movements. However, if the non-random 


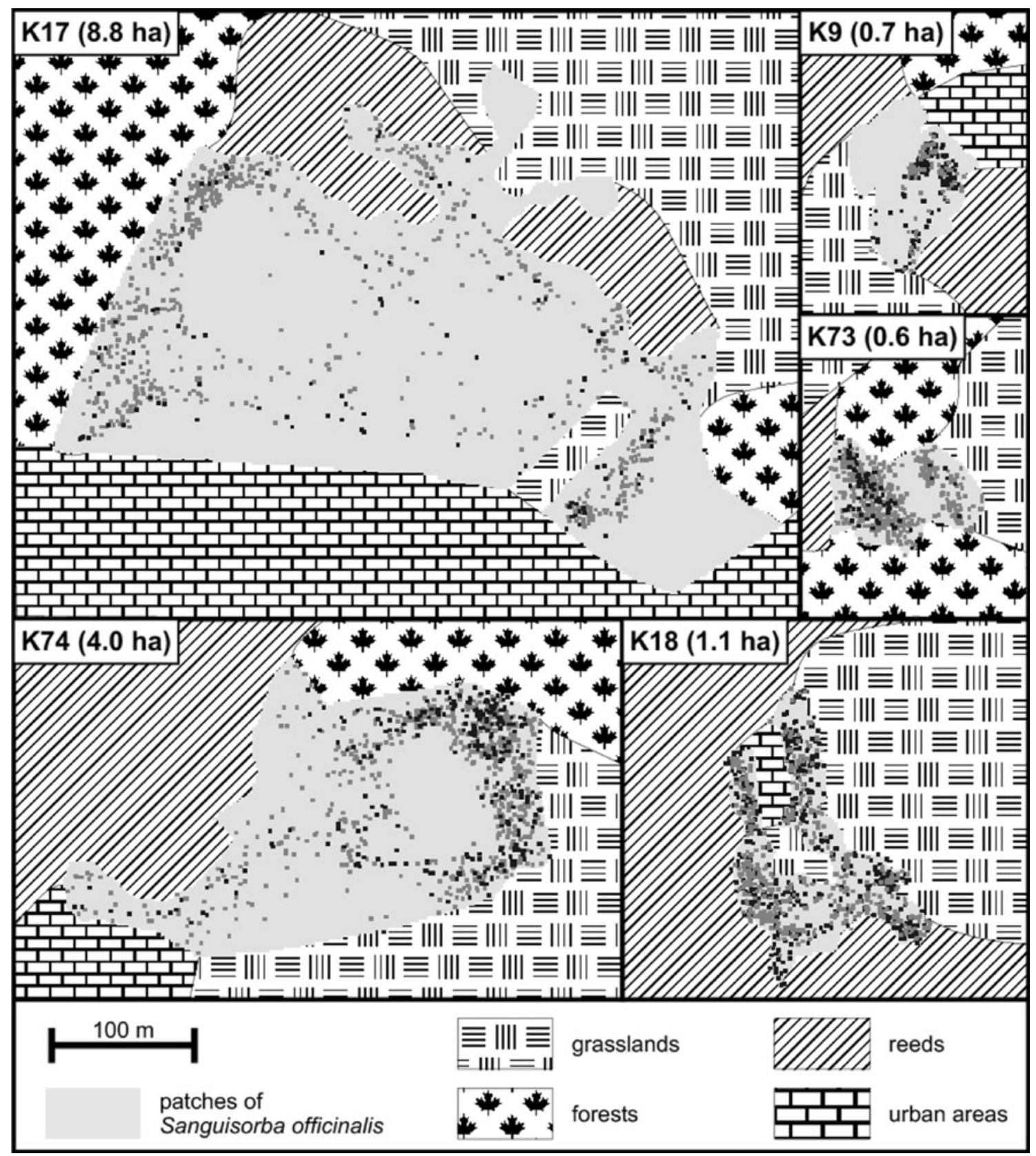

Fig. 1 Schematic maps of the investigated foodplant patches and their surroundings. Patch area is given in each case. Black and gray squares represent capture points of $M$. nausithous and M. teleius respectively

distribution of butterfly capture points results from their edge-constrained movements then one should expect that individuals gradually move towards patch edges during their adult lifetime, and thus their capture locations become closer to patch boundaries. In order to test the above prediction we applied the Wilcoxon matched pairs test to examine distances-from-boundary of consecutive capture points (i.e. 1 st vs. 2 nd, $3 \mathrm{rd}$ vs. 4 th, etc.) of the same individuals.

Finally, we checked whether Maculinea butterflies preferentially select certain zones within their habitat patches. We adopted the number of captures in a particular zone as a measure of its use and proportional share in total patch area as the availability of the zone. The differences between both measures were evaluated with Bailey's (1980) test as recommended by Cherry (1996, 1998). Bailey's test allows calculating confidence intervals for the proportional use of a given zone, which are then compared with its availability: the use significantly exceeding the availability indicates positive preference (i.e. selection), while the use significantly below the availability indicates negative preference (i.e. avoidance). 
Table 1 Numbers of Maculinea butterflies captured and the results of Student's two sample $t$ test for the differences in (log-transformed) distances-from-boundary of male and female capture points

\begin{tabular}{|c|c|c|c|c|c|}
\hline \multirow[t]{2}{*}{ Patch } & \multicolumn{2}{|c|}{ Captured individuals } & \multicolumn{3}{|c|}{ Student's two sample $t$ test } \\
\hline & Males & Females & $d f$ & $t$ & $P$ \\
\hline \multicolumn{6}{|c|}{ M. nausithous } \\
\hline K9 & 60 & 76 & 134 & 0.2708 & 0.7870 \\
\hline K17 & 46 & 58 & 102 & 0.0522 & 0.9585 \\
\hline K18 & 221 & 253 & 472 & -0.1704 & 0.8648 \\
\hline K73 & 16 & 8 & 22 & 0.4804 & 0.6357 \\
\hline K74 & 104 & 64 & 166 & 0.1737 & 0.8622 \\
\hline \multicolumn{6}{|c|}{ M. teleius } \\
\hline K9 & 26 & 39 & 63 & -0.2003 & 0.8420 \\
\hline K17 & 280 & 316 & 594 & -0.6367 & 0.5246 \\
\hline K18 & 164 & 192 & 354 & 0.6021 & 0.5475 \\
\hline K73 & 96 & 101 & 195 & -0.2938 & 0.7692 \\
\hline K74 & 204 & 200 & 402 & -0.2294 & 0.8187 \\
\hline
\end{tabular}

In all the cases the variance was homogenous for both sexes as confirmed with $F$ tests

In the general approach we first defined zones by the distance from patch boundary. They included edge zone ( $<10 \mathrm{~m}$ from patch boundary), transition zone $(10-20 \mathrm{~m})$, central zone (20-40 m), and core zone ( $>40 \mathrm{~m}$, present only in two largest patches). While defining more distance classes might provide more informative results, it was not possible concerning sample size of capture points and the spatial precision of their GPS measurements. In the case of the patches where butterfly preference for the edge zone was detected, we then tested whether any particular type of edges is preferred. Depending on the land use in the areas neighbouring Maculinea habitats we defined grassland edges (adjacent to meadows lacking the Sanguisorba officinalis foodplants), forest edges (adjacent to forests or small woodland fragments), reed edges (adjacent to fallow lands covered with the Phragmites spp reeds), and urban edges (adjacent to residential areas or roads). The analysis was also done using Bailey's (1980) tests, which this time were applied only to capture points located within the edge zones.

\section{Results}

Altogether, we had 1,457 captures of 906 M. nausithous adults and 2,835 captures of 1,618 M. teleius adults. The numbers of individuals captured in each patch are given in the Table 1. The capture points concentrated closer to patch edges than expected for their random distribution, but only at the three largest patches (Fig. 2). On the other hand, there was no evidence that the butterflies move towards patch edges during their adult life-there was no significant change in the distance-from-boundary of consecutive

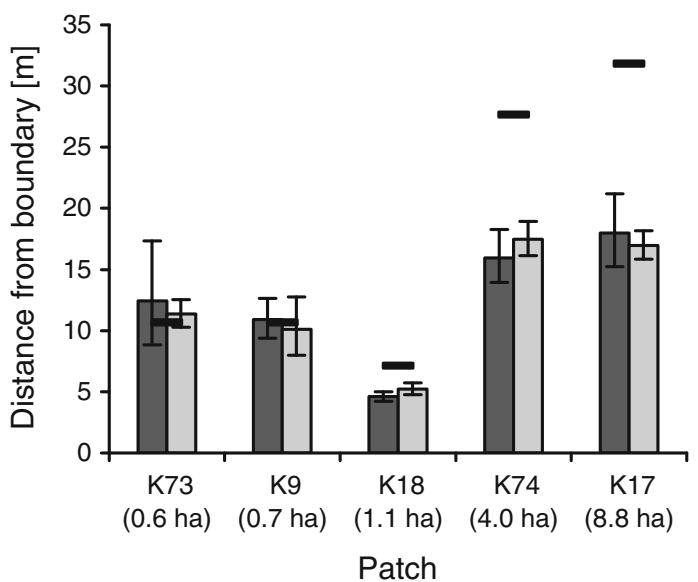

Fig. 2 Distances from habitat patch boundary (mean values with $95 \% \mathrm{CI}$ ) of capture points of Maculinea butterflies: M. nausithousdark gray bars; $M$. teleius - light gray bars. The CIs are asymmetric as the analyses were done on log-transformed data. The mean distances-from-boundary derived for the total surface of each patch with the GIS software Idrisi 2.0 are also presented (solid lines). Habitat patches are ordered according to their increasing area. In all the cases when significant, i.e. for the three larger patches, $P$ values for Student's one sample $t$-test are below 0.0001

captures of the individuals as revealed by outcome of the Wilcoxon test (Table 2). Consequently, there is no support for the hypothesis that butterfly concentrations near patch edges originate from their edge-constrained movements.

The analysis of Maculinea preferences towards different zones within their habitat patches confirmed the aforementioned pattern, indicating that patch interiors, located $>40 \mathrm{~m}$ from patch the boundary, were clearly avoided by both investigated species (Fig. 3). Edge zone was preferred at the three larger patches, but not in the two smaller 
Table 2 Results of the Wilcoxon matched pairs test for distancesfrom-boundary of consecutive captures of the same individuals

\begin{tabular}{lcll}
\hline Patch & \multicolumn{2}{l}{ Wilcoxon test } & \\
\cline { 2 - 4 } & Pairs $(n)$ & $Z$ & \\
\hline M. nausithous & & & \\
K9 & 67 & 0.6965 & 0.4861 \\
K17 & 18 & 0.7621 & 0.4456 \\
K18 & 281 & 0.1243 & 0.9011 \\
K73 & 27 & 0.0240 & 0.9808 \\
K74 & 158 & 0.0659 & 0.9474 \\
M. teleius & & & \\
K9 & 24 & 0.6714 & 0.5019 \\
K17 & 289 & 0.5820 & 0.5606 \\
K18 & 183 & 0.2467 & 0.8052 \\
K73 & 349 & 0.2232 & 0.8233 \\
K74 & 372 & 0.4767 & 0.6335 \\
\hline
\end{tabular}

ones. The only significant result in the analysis of preferences towards different types of edges conducted for the three larger patches was the avoidance of urban edges by M. teleius found at the patches K17 and K74 (Fig. 4). M. nausithous also used urban edges at these patches relatively rarely, but in both cases the statistically significance levels could not be reached due to small sample sizes. In contrast, at patch K18 the use of urban edges by both species exceeded (though rather slightly) their availability (Fig. 4). However, it should be noted that the urban neighbourhood of the K18 patch is represented by a single summerhouse surrounded by an extensive garden thus resembling seminatural habitat, whereas the patches K17 and K74 are bordered by wide asphalt roads and densely built-up areas. No apparent preference towards any other type of edge was detected. Even though to some extent this can be attributed to the low power of Bailey's tests, it should be stressed there was no consistent pattern in the selection of different natural edges across the patches. At the patch K17 both investigated species tended to choose reed edges most frequently (Fig. 4). In turn, forest edges were disproportionately used by $M$. nausithous, and grassland edges by M. teleius, at the patch K74.

\section{Discussion}

Our results indicate clearly that both investigated species of Maculinea butterflies prefer edges of their habitat patches and avoid patch interiors. However, these preferences become visible only at larger patches, which is indeed easily understandable. Smaller patches can be regarded as consisting predominantly of edges (Primack 2002; Fletcher et al. 2007). Consequently, very high proportion of patch
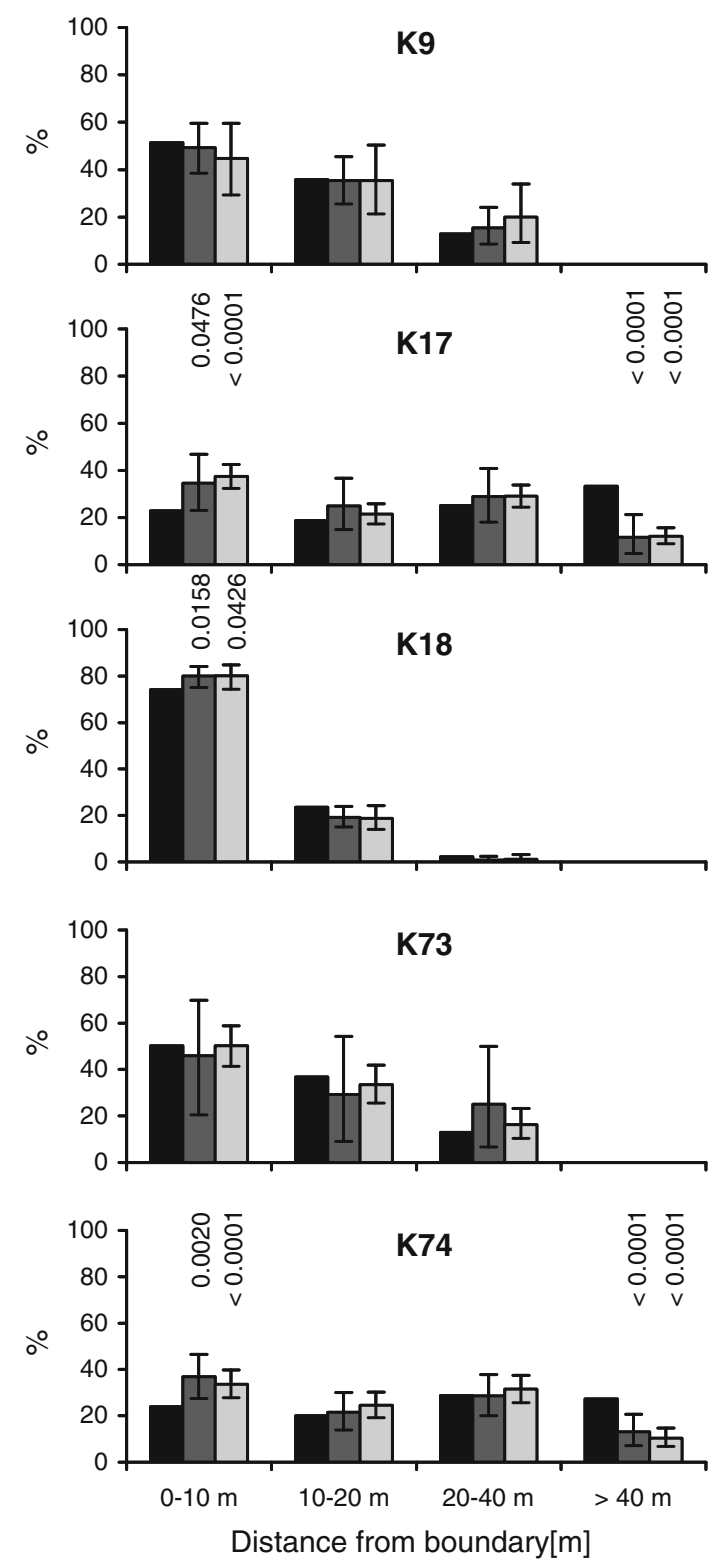

Fig. 3 Preferences of Maculinea butterflies for different zones within their habitat patches: dark gray bars-use by M. nausithous; light gray bars-use by M. teleius (both with $95 \% \mathrm{CI}$ ); black barsavailability. Bailey's test $P$ values are also shown if significant

edges as well as very low (if at all non-zero) proportion of interiors makes it impossible to detect preference for the former and avoidance of the latter. Obviously, the edge proportion is a function of not only patch size, but also its shape. Therefore, the approximately 1 ha threshold value, above which Maculinea preferences for edge zone become detectable at our sites, may not necessarily be true in other regions.

More interestingly, at the patches where edges were preferentially used we found that although edges bordering densely built-up areas are avoided, all types of natural edges seem to be equally selected. In other words, there 

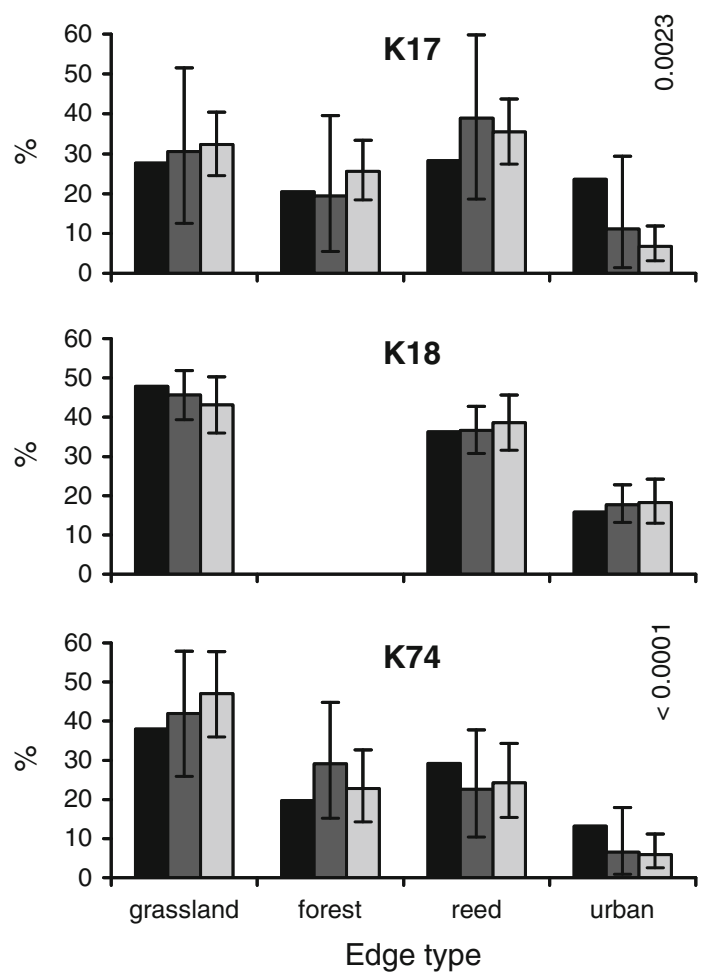

Fig. 4 Preferences of Maculinea butterflies for different edge types at the habitat patches for which preference towards edge zone was detected: dark gray bars - use by M. nausithous; light gray bars-use by M. teleius (both with $95 \%$ CI); black bars—availability. Bailey's test $P$ values are also shown if significant

was no particular preference towards forest edges postulated by Körösi et al. (2012) for M. nausithous, although it should be reminded that forest edges were the only type of patch edges tested in their study. In addition, our results provide no support for the preferential use of road edges by M. teleius reported by Batáry et al. (2009).

Körösi et al. (2012) hypothesised that the preferences they recorded stem from specific microhabitat conditions provided by forest edges. We believe that the pattern can be explained by the spatial interactions between Maculinea butterflies and their Myrmica ant hosts. After ca. 3 weeks of feeding on specific foodplants, Maculinea larvae are adopted by Myrmica ants and spend the rest of their larval life parasitising ant nests (Thomas et al. 1998). Myrmica nests are under strong parasitic pressure from Maculinea within their foodplant patches, whereas patch surroundings, as long as they are natural areas habitable for ants, constitute refuge space for them. Since Myrmica spread mainly through budding of existing colonies over a few meter distance (Hochberg et al. 1994), their abundance may be expected to be higher along edges of foodplant patches and lower in their interiors except for small and/or severely fragmented patches. Consequently, it is beneficial for Maculinea to concentrate along patch edges and lay their eggs there. Whether the butterflies can detect the presence of Myrmica nests is a strongly debated issue. While a few studies suggest they can (van Dyck et al. 2000; Wynhoff et al. 2008; Patricelli et al. 2011), most others indicate that they cannot (e.g. Thomas and Elmes 2001; Nowicki et al. 2005b; Fürst and Nash 2010 and references therein). Nevertheless, it should be underlined that the ability to detect Myrmica nests is not necessary for our explanation of Maculinea preference towards patch edges to be valid. It is equally possible, and in our opinion more likely, that although ant nest abundance is the ultimate cause for Maculinea selecting particular fragments of their habitat patches, patch edges are used as a proximate signal in this respect.

The proposed mechanism of dependence on patch edges is in perfect agreement with the negative density-area relationship reported for local populations of Maculinea butterflies (Nowicki et al. 2007). It also has serious conservation implications indicating the importance of natural patch surroundings for the persistence of Maculinea populations. Both M. nausithous and M. teleius are listed in the Annexes of the Habitats Directive (Van Helsdingen et al. 1996), and consequently many of their localities have been declared Natura 2000 sites in recent years (European Environment Agency 2011). However, the current legal framework of the Natura 2000 system makes the conservation of Maculinea patch surroundings problematic. In many cases, the boundaries of Natura 2000 sites have been designed directly along the boundaries of Maculinea habitat patches, whereas in those where patch surroundings have been encompassed within Natura 2000 sites, they are typically not included in the management regime and thus threatened by development plans (authors' unpubl. data). Therefore, changes in the legal regulations are needed so as to allow setting conservation priorities on the fragments of lands where neither target species nor their habitats occur.

Although extending protection regime to areas surrounding Maculinea habitats is often difficult to achieve, it is worth noting that internal gaps within foodplant patches may have similar positive effect as they are also likely to serve as refuge space for Myrmica ants. At our study sites $S$. officinalis grows at high densities throughout its patches (Nowicki et al. 2007), the same is true for many other localities with M. nausithous and/or M. teleius (Anton et al. 2008; Nowicki et al. 2009; Nowicki and Vrabec 2011; Körösi et al. 2012). Nevertheless, there are also sites, especially in peripheral regions of the European ranges of both species, at which the foodplant is rather sparsely distributed, allowing the existence of empty spaces within its patches (Dierks and Fischer 2009; van Langevelde and Wynhoff 2009). Filling in these gaps, e.g. through planting the foodplant, may intuitively seem a right thing to do for conservation managers as it would increase the area of Maculinea habitats. However, 
our findings suggest that such actions could in fact have a negative impact on Maculinea populations and hence they should be discouraged.

Acknowledgments The study has been funded by the Polish Ministry of Science and Higher Education grant N N304 064139 as well as by the German Federal Ministry of Education and Research within its FP6 BiodivERsA Eranet project CLIMIT. Butterflies were captured with the proper permission from the Polish Ministry of Environment. We would like to express our gratitude to numerous students and staff members of the Institute of Environmental Sciences, Jagiellonian University for their assistance in the fieldwork. Irma Wynhoff and an anonymous reviewer provided valuable comments on the manuscript, while Sarah Gwillym improved its English.

Open Access This article is distributed under the terms of the Creative Commons Attribution License which permits any use, distribution, and reproduction in any medium, provided the original author(s) and the source are credited.

\section{References}

Anton C, Musche M, Hula V, Settele J (2008) Myrmica host-ants limit the density of the antpredatory large blue Maculinea nausithous. J Insect Conserv 12:511-517

Bailey BJR (1980) Large sample simultaneous confidence intervals for the multinomial probabilities based on transformations of the cell frequencies. Technometrics 22:583-589

Batáry P, Körösi A, Örvössy N, Köver S, Peregovits L (2009) Species-specific distribution of two sympatric Maculinea butterflies across different meadow edges. J Insect Conserv 13:223230

Cherry S (1996) A comparison of confidence interval methods for habitat use-availability studies. J Wildl Manage 60:653-658

Cherry S (1998) Statistical tests in publications of The Wildlife Society. Wildlife Soc Bull 26:947-953

Dierks A, Fischer K (2009) Habitat requirements and niche selection of Maculinea nausithous and M. teleius (Lepidoptera: Lycaenidae) within a large sympatric metapopulation. Biodivers Conserv 18:3663-3676

Eastman JR (1997) Idrisi for windows. User's guide version 2.0. Clark University, Worchester

European Environment Agency (2011) Natura 2000 viewer. http://natura2000.eea.europa.eu/. Accessed 20 December 2011

Fahrig L (2003) Effects of habitat fragmentation on biodiversity. Ann Rev Ecol Evol S 34:487-515

Fletcher RJJ, Ries L, Battin J, Chalfou AD (2007) The role of habitat area and edge in fragmented landscapes: definitively distinct or inevitably intertwined? Can J Zool 85:1017-1730

Fürst MA, Nash DR (2010) Host ant independent oviposition in the parasitic butterfly Maculinea alcon. Biol Lett 6:174-176

Haddad NM (1999) Corridor use predicted from behaviors at habitat boundaries. Am Nat 153:215-227

Hambäck PA, Bergman K-O, Bommarco R, Krauss J, Kuussaari M, Pöyry J, Öckinger E (2010) Allometric density responses in butterflies: the response to small and large patches by small and large species. Ecography 33:1149-1156

Hochberg ME, Clarke RT, Elmes GW, Thomas JA (1994) Population dynamic consequences of direct and indirect interactions involving a large blue butterfly and its plant and red ant hosts. J Anim Ecol 63:375-391

Hovestadt T, Nowicki P (2008) Investigating movement within irregularly shaped patches: analysis of mark-release-recapture data using randomization procedures. Isr $\mathrm{J}$ Ecol Evol 54: 137-154

ICZN (2011) Official Lists and indexes of names in zoology, updated December 2011. http://iczn.org/sites/iczn.org/files/listsindexes. pdf. Retrieved 2 April 2012

Kiviniemi K, Eriksson O (2002) Size-related deterioration of seminatural grassland fragments in Sweden. Divers Distrib 8:21-29

Körösi A, Örvössy N, Batáry P, Harnos A, Peregovits L (2012) Different habitat selection by two sympatric Maculinea butterflies at small spatial scale. Insect Conserv Divers 5:118-125

Nowicki P, Vrabec V (2011) Evidence for positive density-dependent emigration in butterfly metapopulations. Oecologia 167:657-665

Nowicki P, Witek M, Skórka P, Settele J, Woyciechowski M (2005a) Population ecology of the endangered butterflies Maculinea teleius and Maculinea nausithous and the implications for conservation. Popul Ecol 47:193-202

Nowicki P, Witek M, Skórka P, Woyciechowski M (2005b) Oviposition patterns in the myrmecophilous butterfly Maculinea alcon Denis \& Schiffermüller (Lepidoptera: Lycaenidae) in relation to characteristics of foodplants and presence of ant hosts. Pol J Ecol 53:409-417

Nowicki P, Pepkowska A, Kudlek J, Skórka P, Witek M, Settele J, Woyciechowski M (2007) From metapopulation theory to conservation recommendations: lessons from spatial occurrence and abundance patterns of Maculinea butterflies. Biol Conserv 140:119-129

Nowicki P, Bonelli S, Barbero F, Balletto E (2009) Relative importance of density-dependent regulation and environmental stochasticity for butterfly population dynamics. Oecologia 161:227-239

Patricelli D, Barbero F, La Morgia V, Casacci LP, Witek M, Balletto E, Bonelli S (2011) To lay or not to lay: oviposition of Maculinea arion in relation to Myrmica ant presence and host plant phenology. Anim Behav 82:791-799

Primack RB (2002) Essentials of conservation biology, 3rd edn. Sinauer Associates, Sunderland

Ries L, Debinski DM (2001) Butterfly responses to habitat edges in the highly fragmented prairies of Central Iowa. J Anim Ecol 70:840-852

Ries L, Sisk TD (2008) Butterfly edge effects are predicted by a simple model in a complex landscape. Oecologia 156:75-86

Ries L, Fletcher RJ, Battin J, Sisk TD (2004) Ecological responses to habitat edges: Mechanisms, models, and variability explained. Ann Rev Ecol Evol S 35:491-522

Schtickzelle N, Baguette M (2003) Behavioural responses to habitat patch boundaries restrict dispersal and generate emigration-patch area relationships in fragmented landscapes. J Anim Ecol 72:533-545

Schultz CB, Crone EE (2001) Edge-mediated dispersal behavior in a prairie butterfly. Ecology 82:1879-1892

Settele J, Kühn E, Thomas JA (2005) Studies on the ecology and conservation of butterflies in Europe. Vol. 2. Species ecology along a European gradient: Maculinea butterflies as a model. Pensoft, Sofia, Bulgaria

Thomas JA, Elmes GW (2001) Food-plant niche selection rather than the presence of ant nests explains oviposition patterns in the myrmecophilous butterfly genus Maculinea. Proc R Soc B 268:471-477

Thomas JA, Clarke RT, Elmes GW, Hochberg ME (1998) Population dynamics in the genus Maculinea (Lepidoptera: Lycaenidae). In: Dempster JP, McLean IFG (eds) Insect population dynamics in theory and practice. Symposia of the royal entomological society 19. Chapman \& Hall, London, pp 261-290

Thomas JA, Simcox DJ, Clarke RT (2009) Successful conservation of a threatened Maculinea butterfly. Science 325:80-83

Thomas JA, Simcox DJ, Hovestadt T (2011) Evidence based conservation of butterflies. J Insect Conserv 15:241-258 
van Dyck H, Oostermeijer JGB, Talloen W, Feenstra V, van der Hidde A, Wynhoff I (2000) Does the presence of ant nests matter for oviposition to a specialized myrmecophilous Maculinea butterfly? Proc R Soc B 267:861-866

van Halder I, Barbaro L, Jactel H (2011) Conserving butterflies in fragmented plantation forests: are edge and interior habitats equally important? J Insect Conserv 15:591-601

Van Helsdingen PJ, Willemse L, Speight MCD (1996) Background information on invertebrates of the habitats directive and the Bern convention. Part I-Crustacea, Coleoptera and Lepidoptera. Nature and Environment, No. 79, Council of Europe, Strasbourg, France van Langevelde F, Wynhoff I (2009) What limits the spread of two congeneric butterfly species after their reintroduction: quality or spatial arrangement of habitat? Anim Conserv 12:540-548

Wynhoff I, Grutters M, van Langevelde F (2008) Looking for the ants: selection of oviposition sites by two myrmecophilous butterfly species. Anim Biol 58:371-388

Yahner RH (1988) Changes in wildlife communities near edges. Conserv Biol 2:333-339

Yamaura Y, Kawahara T, Iida S, Ozaki K (2008) Relative importance of the area and shape of patches to the diversity of multiple taxa. Conserv Biol 22:1513-1522 